\title{
Socio-environmental, personal and behavioural predictors of fast-food intake among adolescents
}

\author{
Katherine W Bauer*, Nicole I Larson, Melissa C Nelson, Mary Story and Dianne \\ Neumark-Sztainer \\ Division of Epidemiology and Community Health, School of Public Health, University of Minnesota, West Bank \\ Office Building, 1300 South 2nd Street - Suite 300, Minneapolis, MN 55454, USA
}

Submitted 1 July 2008: Accepted 4 November 2008: First published online 24 December 2008

\begin{abstract}
Objective: To identify the socio-environmental, personal and behavioural factors that are longitudinally predictive of changes in adolescents' fast-food intake.

Design: Population-based longitudinal cohort study.

Setting: Participants from Minnesota schools completed in-class assessments in 1999 (Time 1) while in middle school and mailed surveys in 2004 (Time 2) while in high school.

Subjects: A racially, ethnically and socio-economically diverse sample of adolescents ( $n$ 806).

Results: Availability of unhealthy food at home, being born in the USA and preferring the taste of unhealthy foods were predictive of higher fast-food intake after 5 years among both males and females. Among females, personal and behavioural factors, including concern about weight and use of healthy weight-control techniques, were protective against increased fast-food intake. Among males, socio-environmental factors, including maternal and friends' concern for eating healthy food and maternal encouragement to eat healthy food, were predictive of lower fast-food intake. Sports team participation was a strong risk factor for increased fast-food intake among males.

Conclusions: Our findings suggest that addressing socio-environmental factors such as acculturation and home food availability may help reduce fast-food intake among adolescents. Additionally, gender-specific intervention strategies, including working with boys' sports teams, family members and the peer group, and for girls, emphasizing the importance of healthy weight-maintenance strategies and the addition of flavourful and healthy food options to their diet, may help reduce fast-food intake.
\end{abstract}

\section{Keywords \\ Fast food \\ Adolescents \\ Dietary intake}

Eating at fast-food restaurants is common among adolescents. National data indicate that on any given day nearly $40 \%$ of high-school-aged adolescents report consuming food from a fast-food restaurant ${ }^{(1)}$. In the late 1970 s, fast food comprised only $2 \%$ of children and adolescents' total energy intake, while in the mid-1990s it rose to $10 \%$ of their total energy intake ${ }^{(2)}$. This trend of increased intake from fast-food restaurants shows little evidence of slowing down, with these restaurants commonly located within walking distance of schools ${ }^{(3,4)}$, fast-food meals being served in school cafeterias ${ }^{(5)}$, open school campus policies that allow students to leave and purchase fast food for lunch ${ }^{(6)}$, and excessive marketing of fast food to children and adolescents ${ }^{(7,8)}$.

Frequently eating at fast-food restaurants may have adverse consequences for nutritional intake and weightrelated health. Common adolescent food choices from fast-food restaurants, including hamburgers, pizza, French fries and sugar-sweetened beverages ${ }^{(9)}$, which are frequently served in large portions ${ }^{(10)}$, can contribute to poor nutritional intake. Among children, adolescents and adults, fast-food consumption has been associated with higher $\mathrm{BMI}^{(11)}$, weight gain ${ }^{(12,13)}$ and decreased insulin sensitivity ${ }^{(12)}$. Additionally, those with high fastfood intake report higher intakes of total energy, total fat, saturated fat, carbohydrates, $\mathrm{Na}$, added sugar and sugar-sweetened beverages, and lower intakes of milk, fruits and vegetables ${ }^{(1,11,13-16)}$.

In order to better understand and ultimately curb the consumption of fast food among adolescents, it is important to understand what factors contribute to fastfood intake. In particular, understanding the factors that predict fast-food intake during the transition from middle to high school, when adolescents become increasingly 
independent and have great access to unhealthy dietary choices, may be especially important. This knowledge can inform public health interventions aiming to improve adolescents' dietary intake and help them achieve a healthy weight status.

Examining the cross-sectional data from Project EAT (Eating Among Teens), French and colleagues ${ }^{(17)}$ identified several correlates of adolescents' fast-food intake such as dislike for the taste of healthy foods, perceived lack of time to eat healthy foods, sports team participation, high television usage, and lack of maternal or peer concern for healthy eating. Additional cross-sectional and longitudinal studies have identified the frequency of television viewing, and acculturation and US nativity among members of racial and ethnic minority groups, as risk factors for adolescents' fast-food consumption ${ }^{(18-20)}$. Cross-sectional studies of adults have found that similar factors are correlated with adult's fast-food intake, such as television viewing ${ }^{(21)}$, as well as additional factors such as perceived difficulty in preparing healthy foods and self-efficacy for eating fruits and vegetables ${ }^{(22)}$.

The current study uses data from Project EAT to build upon the previous cross-sectional analysis to identify socio-environmental, personal and behavioural factors, as suggested by Social Cognitive Theory, that longitudinally predict fast-food intake among high-school-aged adolescents. Using these data drawn from a population-based, 5-year longitudinal study, we examined the relationship between the socio-environmental, personal and behavioural factors which were reported by adolescents during middle school and their fast-food consumption during high school. The present study is one of the few theory-based, longitudinal studies to examine a diverse set of potential predictors of adolescents' fast-food intake. By examining longitudinal relationships between the selected factors and fast-food intake, we are not only able to determine whether these factors are associated with fast-food intake among adolescents, but also whether they predict long-term increases in fast-food intake through the adolescent years.

\section{Methods}

\section{Sample and study design}

Data for the current study were drawn from Project EAT (Eating Among Teens), a prospective, population-based study designed to examine determinants of dietary intake and weight status. Project EAT surveyed middle- and high-school students in 1998-9, and then resurveyed participants again five years later in 2003-4 in order to examine how socio-environmental, personal and behavioural factors may influence adolescents during the transitions from middle to high school and high school into young adulthood. The sample used in the present analysis consisted of the 806 adolescents who were in middle school at baseline (EAT-I) and in high school at follow-up five years later (EAT-II). At baseline the mean age of participants was $12 \cdot 8(\mathrm{sD} 0 \cdot 8)$ years and at followup their mean age was $17 \cdot 2(\mathrm{SD} 0 \cdot 6)$ years.

For Project EAT-I (1998-9), 1672 middle-school students completed the Project EAT-I survey and FFQ in their classrooms. Five years later, Project EAT-II (2003-4) aimed to resurvey by mail all original participants for whom contact information was available. Of those in the middle-school cohort for whom contact information was available, $69 \cdot 5 \%$ completed the follow-up survey. This represents $50 \cdot 1 \%$ of the original cohort. All study protocols were approved by the University of Minnesota's Institutional Review Board Human Subjects Committee.

\section{Surveys and measures}

The development of the baseline Project EAT-I survey was guided by Social Cognitive Theory ${ }^{(23)}$, focus group discussions with adolescents ${ }^{(24)}$, an in-depth literature review and pilot testing. The majority of these items were retained without modification for the Project EAT-II follow-up survey completed by high-school students.

\section{Outcome measure}

Fast-food intake was assessed at baseline and follow-up using a single item on the Project EAT surveys: 'In the past week, how often did you eat something from a fast-food restaurant (like McDonald's, Burger King, Hardee's, etc)?' Six response categories ranged from 'never' to 'more than 7 times'. Several other studies examining fast-food intake have used a similar item to measure fast-food intake among adolescents ${ }^{(14,25)}$. We collapsed the fast-food intake response categories into 0 times in the past week (low intake), 1-2 times in the past week (moderate intake) and 3 or more times in the past week (frequent intake $)^{(17,26)}$. Increased fast-food intake assessed using this question, and represented in these three categories, has been positively correlated with adolescents' intakes of total energy, fat energy, saturated fat energy, Na, French fries and soft drinks ${ }^{(17)}$.

\section{Exposure measures}

Socio-environmental, personal and behavioural characteristics were assessed at baseline during Project EAT-I. Table 1 contains these variables along with psychometric information when available.

\section{Covariates}

Race/ethnicity and socio-economic status (SES) were based on adolescents' self-report in Project EAT-I. Race/ethnicity was assessed at baseline with the question: 'Do you think of yourself as...?', with responses of white, black or AfricanAmerican, Hispanic or Latino, Asian-American, Hawaiian or Pacific Islander, or American Indian or Native American. Subjects could choose more than one category; responses indicating multiple categories were coded as 'mixed or 
Table 1 Description of the socio-environmental, personal and behavioural measures assessed in the present study

Socio-environmental factors

Adult supervision

Healthy food available

Unhealthy food available

Family meals

Mom working

Dad working

Maternal concern with healthy eating

Maternal encouragement for my healthy eating

Paternal concern with healthy eating

Paternal encouragement for my

healthy eating

Friends' concern for healthy eating

Friends dieting

Personal factors

Born outside the USA

Self-report BMI

Nutrition knowledge

Benefits of healthy eating

Barriers to healthy eating convenience

Preference for unhealthy food

Self-efficacy for healthy eating

Weight concerns

Weight perception

Behavioural factors

Healthy weight-control behaviours

Unhealthy weight-control behaviours

Substance use

Sports team participation

Work for pay

Vegetarian

Television viewing
'On how many of the past 7 days was at least one of your parents in the room with you when you ate dinner?' (responses options: 'never' to 'every day') and 'Is there an adult at home at the following time? (1) Before you go to school in the mornings; (2) When you arrive home from school in the afternoon; (3) In the early evening - about 6 pm; (4) When you go to bed at night' (response options: 'almost never' to 'almost always'). Cronbach's $\alpha=0.62$

'How often are the following true? (1) Fruits and vegetables are available in my home; (2) Milk is served at meals in my home; (3) We have fruit juice in my home; (4) Vegetables are served at dinner in my home' (response options: 'never' to 'always'). Cronbach's $\alpha=0.63$

'How often are the following true? (1) We have 'junk food' in my home; (2) Potato chips or other salty snack foods are available in my home; (3) Chocolate or other candy is available in my home;

(4) Soda pop is available at home' (response options: 'never' to 'always'). Cronbach's $\alpha=0.80$

'During the past 7 days, how many times did all, or most, of your family living in your house eat a meal together?' (response options: 'never' to 'more than 7 times')

'Does your mother...?' (response options: 'not work for pay', 'work part-time for pay', 'work full-time for pay')

'Does your father...?' (response options: 'not work for pay', 'work part-time for pay', 'work full-time for pay')

'My mother cares about eating healthy food' (response options: 'not at all' to 'very much')

'My mother encourages me to eat healthy food' (response options: 'not at all' to 'very much')

'My father cares about eating healthy food' (response options: 'not at all' to 'very much')

'My father encourages me to eat healthy food' (response options: 'not at all' to 'very much')

'Many of my friends care about eating healthy food' (response options: 'not at all' to 'very much')

'Many of my friends diet to lose weight or keep from gaining weight' (response options: 'not at all' to 'very much')

'Were you born in the United States?'

'How tall are you?' and 'How much do you weigh?' BMI = (weight in $\mathrm{kg}) /\left[\left(\right.\right.$ height in metres) $\left.{ }^{2}\right]$

'For each question below, please select the food you think is better for your health'; seven pairs of food items. Cronbach's $\alpha=0.63$

'The types of food I eat affect... (1) My health; (2) How I look; (3) My weight; (4) How well I do in sports; (5) How well I do in school' (response options: 'strongly disagree' to 'strongly agree'). Cronbach's $\alpha=0.83$

'How strongly do you agree with the following statements? (1) I am too busy to eat healthy foods; (2) I am too rushed in the morning to eat a healthy breakfast; (3) Eating healthy meals just takes too much time; (4) I don't have time to think about healthy eating' (response options: 'strongly disagree' to 'strongly agree'). Cronbach's $\alpha=0.71$

'How strongly do you agree with the following statements? (1) I like the taste of potato chips and other salty snack foods; (2) Milk tastes good to me (reverse scored); (3) Most unhealthy foods taste better than healthy foods; (4) I like the taste of most fruits (reverse scored); (5) Most vegetables taste bad; (6) Most healthy foods just don't taste that great' (response options: 'strongly disagree' to 'strongly agree'). Cronbach's $\alpha=0.53$

'If you wanted to, how sure are you that you could eat healthy food when you are... (1) At the mall; (2) Hungry after school; (3) With your friends; (4) Stressed out; (5) Feeling down; (6) Bored; (7) At a fast-food restaurant; (8) Alone; (9) Eating dinner with your family?' (response options: 'not at all sure' to 'very sure'). Cronbach's $\alpha=0.83$

'How strongly do you agree with the following statements? (1) I think a lot about being thinner; (2) I am worried about gaining weight; (3) I weigh myself often; (4) I sometimes skip meals since I am concerned about my weight' (response options: 'strongly disagree' to 'strongly agree').

Cronbach's $\alpha=0.82$

'At this time, do you feel that you are...?' (response options: 'very underweight' to 'very overweight')

'Have you done any of the following things in order to lose weight or keep from gaining weight during the past year? (1) Exercise; (2) Ate more fruits and vegetables; (3) Ate less high-fat foods; (4) Ate less sweets' (response options: yes/no). Cronbach's $\alpha=0.81$

'Have you done any of the following things in order to lose weight or keep from gaining weight during the past year? (1) Fasted; (2) Ate very little food; (3) Used food substitute (e.g. Slim-Fast); (4) Skipped meals; or (5) Smoked more cigarettes' (response options: yes/no). Cronbach's $\alpha=0.70$

'How often have you used the following during the past year (12 months)? (1) Cigarettes; (2) Beer, wine, hard liquors; (3) Marijuana; (4) Drugs other than marijuana (acid, cocaine, crack, etc.) (response options: 'never' to 'daily'). Cronbach's $\alpha=0.79$

'During the past 12 months, on how many sports teams did you play?' (four response categories ranging from ' 0 teams' to ' 3 or more teams'; responses were dichotomized into 0 or 1 or more)

'How many hours do you work for pay in a typical week during the school year?' (response options: 'none' to 'over 20 hours a week')

'Are you a vegetarian?' (response options: yes/no)

'In your free time on an average weekday, how many hours do you spend watching TV \& videos?' and 'In your free time on an average weekend day (Saturday or Sunday) how many hours do you spend watching TV \& videos?' (response options: '0 hours' to '5+ hours') 
other'. Due to the small number of respondents in some of the racial/ethnic categories, Hawaiian or Pacific Islander, American Indian or Native American and mixed heritage were combined to form an 'other' category in the analysis. The primary determinant of SES was parental educational level, defined by the highest level of educational attainment of either parent. In addition, an algorithm was developed to take into account family eligibility for public assistance, eligibility for free or reduced-cost school meals and employment status of the mother and the father ${ }^{(27)}$.

\section{Statistical analyses}

Of the 806 high-school-aged adolescents who provided follow-up survey data, exclusions were made for those missing data on fast-food intake ( $n$ 14). Data were weighted to adjust for differential response rates to Projects EAT-I and EAT-II using the response propensity method $^{(28)}$. The weighted ethnic/racial and SES proportions of the study sample were as follows: $33 \cdot 3 \%$ white, $22.9 \%$ Asian-American, 24.2\% African-American, 6.5\% Hispanic and $13.9 \%$ mixed or other race; whereas SES percentages were $17 \cdot 2 \%$ low, $18 \cdot 6 \%$ low-middle, $31 \cdot 0 \%$ middle, $18.3 \%$ upper-middle and $14.9 \%$ high.

Several analyses were conducted to examine the relationships between sociodemographic characteristics and fast-food intake. The $\chi^{2}$ test was used to examine associations of the three-level fast-food intake variable with race/ethnicity in five categories and SES in five categories. ANOVA was used to compare the mean ages of participants in each of the three levels of fast-food intake.

To separately examine associations between each of the potential socio-environmental, personal and behavioural predictors assessed at baseline with follow-up fast-food intake, ordinal logistic regression analyses were conducted on the three-level dependent fast-food intake variable using two models. Model 1 controlled for baseline race/ethnicity in two categories (white/non-white) and SES in five categories. Model 2 controlled for baseline race/ethnicity, SES and fast-food intake during EAT-I. Model 1 was used to examine the total association of potential correlates with fast-food intake at follow-up, while Model 2 was used to examine associations between potential correlates and change in fast-food intake over the 5-year study period. All analyses were stratified by gender.

For Models 1 and 2, non-dichotomous personal, behavioural and socio-environmental variables were standardized to allow for relative comparisons of strength between the observed associations. Models for every potential correlate satisfied the proportionality of odds assumption for ordinal logistic regression, indicating that the odds ratios for being in either of the two higher intake categories (frequent or moderate) $v$. the lowest intake category (low) were not statistically different from the odds ratios for being in the highest intake category (frequent) $v$. either of the two lower intake categories (moderate or low). $P<0.05$ from a two-sided test of significance was used to direct attention to statistically significant results. Analyses were conducted using the Statistical Analysis System (SAS) statistical software package version $8 \cdot 2$ (SAS Institute, Cary, NC, USA).

\section{Results}

At follow-up, approximately one-third of both males $(31 \cdot 2 \%)$ and females $(30 \cdot 9 \%)$ reported frequent consumption of fast food ( 3 or more times in the past week). One-fifth of males $(21 \cdot 2 \%)$ and females $(21 \cdot 8 \%)$ reported low consumption of fast food ( 0 times in the past week). Among females, fast-food intake differed by race/ethnicity, SES and age (Table 2). A higher percentage of white and Asian girls were low fast-food consumers (26.2\% and $26.7 \%$, respectively) compared with girls of the other racial/ethnic backgrounds. Compared with girls from higher SES families, low-SES girls were more likely to report frequent fast-food consumption. Females in the frequent fast-food category were more likely to be older than those females in the moderate and low intake categories. Fast-food intake was not associated with any of these sociodemographic variables among males.

\section{Associations of socio-environmental, personal and behavioural variables with fast-food intake at follow-up}

Among males, many of the Time 1 variables that predicted fast-food intake at Time 2 were from the domain of the social environment (Table 3). After controlling for sociodemographic characteristics, socio-environmental factors that were protective against higher fast-food intake included maternal concern with her own healthy eating (Model 1: $\mathrm{OR}=0 \cdot 70, \quad P=0 \cdot 002)$, maternal encouragement of the adolescent to eat healthy food (Model $1:$ OR $=0 \cdot 80$, $P=0 \cdot 04)$ and friends' concern for eating healthy food (Model 1: OR $=0 \cdot 76, P=0 \cdot 03$ ). For each standard deviation increase in the adolescents' report at Time 1 that their friends cared about eating healthy food, there was a $26 \%$ decreased odds of adolescents being in a higher fast-food intake category at Time 2 , e.g. being a frequent $v$. moderate fast-food consumer. Availability of unhealthy food in the home was also a socio-environmental risk factor for higher fast-food intake (Model 1: $\mathrm{OR}=1 \cdot 29, P=0 \cdot 02$ ). After adjustment for Time 1 fast-food intake (Model 2), the inverse relationship between maternal concern with her own healthy eating and adolescents' fast-food intake remained, therefore maternal concern for healthy food was associated with a $27 \%$ lower odds of increasing to the next higher fast-food intake category at Time $2(\mathrm{OR}=0 \cdot 73$, $P=0 \cdot 005)$. In addition to these socio-environmental factors, being born outside the USA was protective against increased fast-food intake among males (Model 2: OR = $0 \cdot 45, P=0 \cdot 006$ ), while Time 1 television viewing (Model 2 : $\mathrm{OR}=1 \cdot 24, P=0 \cdot 04)$ and participating on a sports team 
Table 2 Time 2 fast-food Intake among male and female participants in Project EAT according to sociodemographic characteristics* $\dagger$

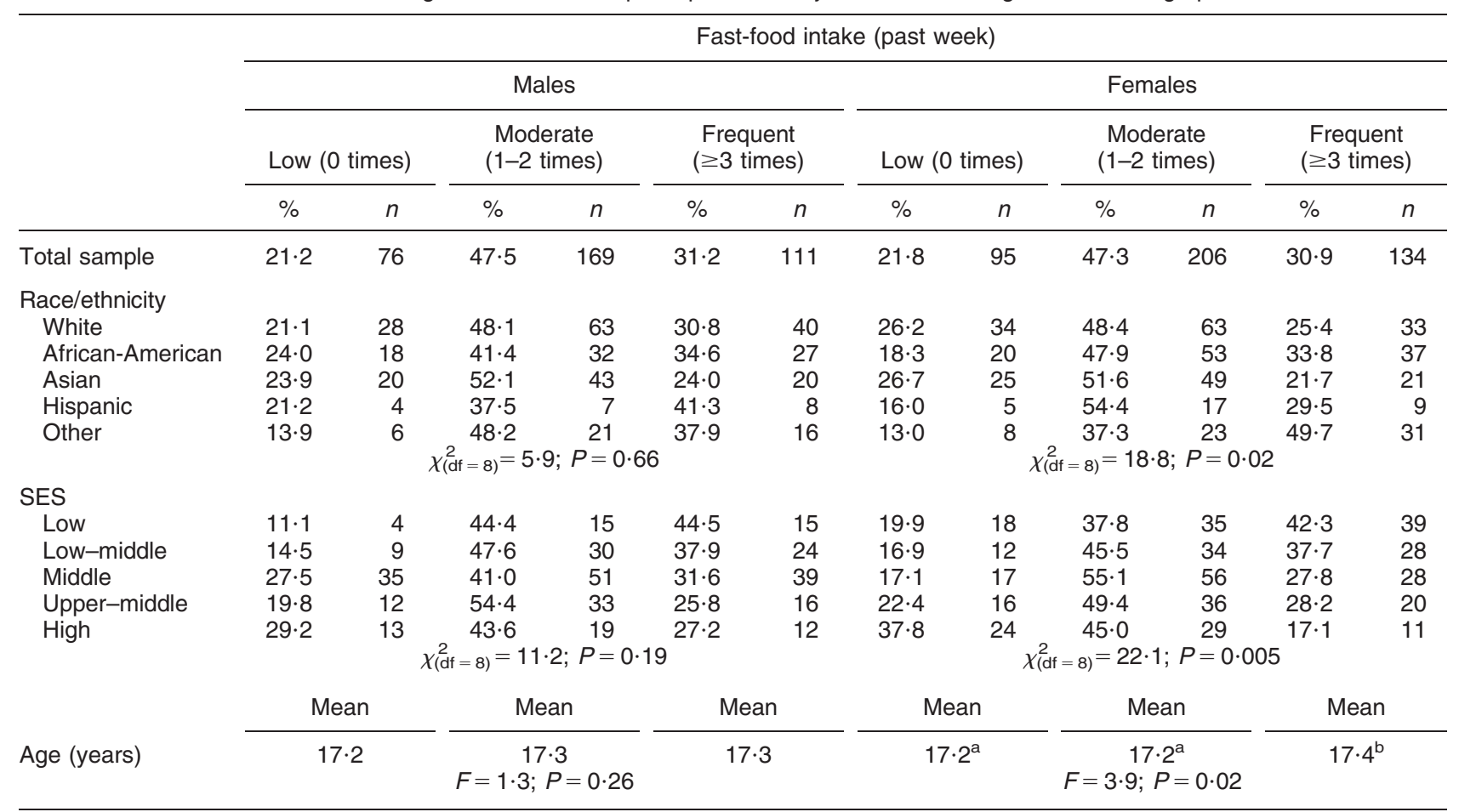

SES, socio-economic status.

${ }^{a, b}$ Mean values with unlike superscript letters were significantly different.

${ }^{*}$ Adjusted frequencies, means and percentages were determined using response propensity weights. Race/ethnicity and SES status were assessed at baseline. Age was assessed at follow-up.

tThe sample size for different variables may vary from the total sample size because of missing responses.

(Model 2: $\mathrm{OR}=2 \cdot 17, \quad P=0 \cdot 001$ ) were risk factors for increased fast-food intake at Time 2 .

Among females, several of the personal and behavioural factors reported at Time 1 were significantly associated with both higher fast-food consumption (Model 1) and increased fast-food consumption (Model 2) at Time 2 (Table 3). Weight concerns (Model 2: $\mathrm{OR}=0 \cdot 79, P=0 \cdot 02$ ) and using healthy weight-control strategies such as exercising and eating fruits and vegetables in order to lose weight (Model 2: $\mathrm{OR}=0 \cdot 78, P=0 \cdot 008$ ) were protective against increased fast-food intake at Time 2. Meanwhile, preferring the taste of unhealthy foods was a risk factor for increased fast-food consumption at Time 2 (Model 2: OR $=1 \cdot 28, P=0 \cdot 01$ ). Having been born outside the USA was a strong protective factor against increased fast-food intake at Time 2, with those born outside the USA being approximately 50\% less likely to increase to a higher fast-food consumption category at Time 2 (Model 2: $\mathrm{OR}=0 \cdot 45, P=0 \cdot 004$ ). The sole socio-environmental predictor of increased fast-food intake among females was having unhealthy food available in the home (Model 2: OR $=1 \cdot 34, P=0 \cdot 004)$.

\section{Discussion}

The goal of the present study was to identify socioenvironmental, personal and behavioural factors that longitudinally predict fast-food intake among highschool-aged adolescents. Frequent fast-food intake was common among our follow-up sample of high-school students; almost one-third of adolescents reported eating fast food at least three times in the previous week. Several socio-environmental, personal and behavioural factors, as assessed during middle school, were identified as longitudinal predictors of fast-food intake five years later during high school.

Many of the predictors of fast-food intake among males were socio-environmental factors, including friends' concern for healthy eating and the home food environment. Of specific interest is the strong protective relationship between maternal concern for healthy eating and males' fast-food intake, which remained after adjustment for baseline fast-food intake. Although the other significant predictors of males' fast-food intake, being born outside the USA and participating on sports teams, were categorized as personal and behavioural based on our use of the Social Cognitive Theory, it may be that the socio-cultural aspects of these factors play a role in males' fast-food intake. Expanding on the cross-sectional analysis of baseline data from Project EAT-I ${ }^{(17)}$, the current study found that males' sports team participation in middle school predicted increased fast-food intake during the high school years. Of all the factors examined in the present study, sports team participation in middle school was the 
Table 3 Socio-environmental, personal and behavioural predictors of fast-food intake at follow-up in Project EAT participants

\begin{tabular}{|c|c|c|c|c|c|c|c|c|}
\hline & \multicolumn{4}{|c|}{ Males ( $n$ 335) } & \multicolumn{4}{|c|}{ Females (n 409) } \\
\hline & \multicolumn{2}{|c|}{ Model $1^{*}$} & \multicolumn{2}{|c|}{ Model $2+$} & \multicolumn{2}{|c|}{ Model $1^{*}$} & \multicolumn{2}{|c|}{ Model $2 \dagger$} \\
\hline & OR & $P$ & OR & $P$ & OR & $P$ & OR & $P$ \\
\hline \multicolumn{9}{|l|}{ Socio-environmental factors } \\
\hline Adult supervision & $1 \cdot 04$ & $0 \cdot 71$ & $1 \cdot 11$ & 0.34 & 0.91 & 0.35 & 0.92 & $0 \cdot 40$ \\
\hline Healthy food available & $0 \cdot 84$ & $0 \cdot 14$ & $0 \cdot 81$ & 0.09 & 0.90 & $0 \cdot 28$ & 0.91 & $0 \cdot 33$ \\
\hline Unhealthy food available & $1 \cdot 29$ & 0.02 & $1 \cdot 16$ & $0 \cdot 18$ & $1 \cdot 38$ & 0.001 & $1 \cdot 34$ & 0.004 \\
\hline Family meals & 0.84 & $0 \cdot 11$ & 0.85 & $0 \cdot 13$ & $0 \cdot 89$ & 0.23 & $0 \cdot 89$ & 0.23 \\
\hline Mom working & $1 \cdot 21$ & 0.09 & $1 \cdot 22$ & 0.09 & $1 \cdot 17$ & $0 \cdot 14$ & $1 \cdot 16$ & $0 \cdot 15$ \\
\hline Dad working & $1 \cdot 20$ & $0 \cdot 13$ & $1 \cdot 22$ & 0.09 & 0.95 & 0.68 & 0.94 & 0.61 \\
\hline Maternal concern with healthy eating & $0 \cdot 70$ & 0.002 & 0.73 & 0.005 & 0.94 & 0.50 & 0.93 & 0.49 \\
\hline Maternal encouragement for my healthy eating & $0 \cdot 80$ & 0.04 & $0 \cdot 85$ & $0 \cdot 12$ & $0 \cdot 91$ & $0 \cdot 37$ & 0.93 & 0.45 \\
\hline Paternal concern with healthy eating & 0.82 & 0.06 & 0.84 & $0 \cdot 11$ & $0 \cdot 87$ & $0 \cdot 16$ & $0 \cdot 87$ & $0 \cdot 18$ \\
\hline Paternal encouragement for my healthy eating & 0.90 & $0 \cdot 33$ & 0.95 & $0 \cdot 64$ & $0 \cdot 88$ & $0 \cdot 21$ & $0 \cdot 89$ & $0 \cdot 25$ \\
\hline Friends concern for healthy eating & $0 \cdot 76$ & 0.03 & $0 \cdot 80$ & 0.07 & $0 \cdot 86$ & $0 \cdot 19$ & $0 \cdot 88$ & 0.28 \\
\hline Friends dieting & 0.85 & $0 \cdot 20$ & 0.83 & $0 \cdot 17$ & 0.94 & $0 \cdot 61$ & 0.93 & 0.52 \\
\hline \multicolumn{9}{|l|}{ Personal factors } \\
\hline Born outside the USA & 0.46 & 0.006 & 0.45 & 0.006 & 0.46 & 0.005 & 0.45 & 0.004 \\
\hline Self-report BMI & 0.93 & 0.48 & 0.98 & $0 \cdot 87$ & 1.03 & $0 \cdot 77$ & 1.02 & $0 \cdot 86$ \\
\hline Nutrition knowledge & $1 \cdot 00$ & 0.97 & $1 \cdot 11$ & $0 \cdot 36$ & 0.86 & $0 \cdot 16$ & 0.89 & 0.28 \\
\hline Benefits of healthy eating & 0.92 & 0.43 & 0.95 & 0.63 & 0.94 & 0.54 & 0.97 & $0 \cdot 74$ \\
\hline Barriers to healthy eating - convenience & $1 \cdot 19$ & $0 \cdot 11$ & $1 \cdot 11$ & $0 \cdot 33$ & $1 \cdot 12$ & $0 \cdot 26$ & 1.09 & $0 \cdot 39$ \\
\hline Preference for unhealthy food & $1 \cdot 29$ & 0.02 & $1 \cdot 21$ & 0.09 & $1 \cdot 33$ & 0.003 & $1 \cdot 28$ & 0.01 \\
\hline Self-efficacy for healthy eating & 0.83 & 0.08 & $0 \cdot 84$ & $0 \cdot 10$ & $1 \cdot 04$ & 0.69 & $1 \cdot 08$ & 0.44 \\
\hline Weight concerns & 0.94 & 0.55 & 0.96 & $0 \cdot 73$ & $0 \cdot 81$ & 0.02 & 0.79 & 0.02 \\
\hline Weight perception & 0.91 & 0.37 & 0.95 & $0 \cdot 60$ & $0 \cdot 84$ & 0.07 & $0 \cdot 83$ & 0.06 \\
\hline \multicolumn{9}{|l|}{ Behavioural factors } \\
\hline Healthy weight-control behaviours & 0.86 & $0 \cdot 15$ & 0.90 & 0.30 & 0.79 & 0.01 & $0 \cdot 78$ & 0.008 \\
\hline Unhealthy weight-control behaviours & 0.89 & $0 \cdot 26$ & $0 \cdot 89$ & 0.27 & 0.93 & 0.43 & 0.92 & $0 \cdot 38$ \\
\hline Substance use & $1 \cdot 12$ & 0.33 & $1 \cdot 08$ & 0.53 & $1 \cdot 01$ & $0 \cdot 22$ & 0.98 & $0 \cdot 81$ \\
\hline Sports team participation & $2 \cdot 36$ & 0.0003 & $2 \cdot 17$ & 0.001 & $1 \cdot 35$ & $0 \cdot 14$ & $1 \cdot 33$ & $0 \cdot 16$ \\
\hline Work for pay & $1 \cdot 12$ & $0 \cdot 28$ & $1 \cdot 11$ & $0 \cdot 34$ & $1 \cdot 16$ & $0 \cdot 15$ & $1 \cdot 15$ & $0 \cdot 18$ \\
\hline Vegetarian & $1 \cdot 40$ & 0.52 & $1 \cdot 35$ & 0.57 & $1 \cdot 41$ & 0.32 & $1 \cdot 42$ & $0 \cdot 31$ \\
\hline Television viewing & $1 \cdot 29$ & 0.02 & $1 \cdot 24$ & 0.04 & 1.00 & 0.63 & 1.00 & $0 \cdot 87$ \\
\hline
\end{tabular}

*Model 1 adjusted for baseline socio-economic status (SES) in five categories and race/ethnicity (white/non-white).

tModel 2 adjusted for baseline SES, race/ethnicity and fast-food intake at Time 1.

strongest risk factor for fast-food intake in high school. This relationship may emerge because adolescents who are on sports teams have little time for meals at home and therefore may rely on fast food for quick meals.

Among females, a pattern of personal and behavioural predictors of fast-food intake emerged. These include weight concerns, healthy weight-control behaviours and taste preference for unhealthy foods. All of the predictors of fast-food intake among females remained after controlling for baseline fast-food intake. Therefore, they were not only associated with higher fast-food intake in high school but an increase in intake between middle and high school. Similar to males, being born outside the USA was associated with fast-food intake in high school. These findings support those of other cross-sectional and longitudinal studies which have found that first-generation immigrants and less acculturated adolescents and adults often have better dietary intake patterns, including lower consumption of fast food, compared with their US-native and acculturated peers ${ }^{(20,29)}$

These patterns of longitudinal predictors can help guide intervention strategies to reduce adolescents' fastfood intake. Findings from the current study suggest that both males and females may benefit from interventions that aim to decrease the availability of unhealthy foods in the home. Additionally, adolescents whose families have recently immigrated to the USA may benefit from interventions that emphasize the maintenance of healthier, culturally specific eating patterns from their native countries. Meanwhile, some gender-specific strategies may be appropriate for reducing fast-food intake. For boys, it may be important to address the strong association between sports team participation and fast-food intake. One strategy to address this may be ensuring that team practices end early enough in the evening so that families are able to prepare a family meal at home. Programmes that aim to modify girls' personal beliefs and behaviours may be successful in reducing their fast-food intake. Interventions for girls may choose to focus on encouraging girls to use healthy weight-management strategies such as eating fruits and vegetables, choosing low-fat food options, and trying new, healthy foods in the hope of finding several that they enjoy and can integrate into their daily intake.

The results of the current study align well with the findings of previous cross-sectional studies in adolescent ${ }^{(17,19)}$ and adult ${ }^{(21,22)}$ populations. In a separate analysis of 
longitudinal predictors of fast-food intake among the young adult population that participated in Project EAT, Larson et $a l^{(26)}$ similarly found that peer support for healthy eating predicted decreased consumption of fast food among males, while personal and behavioural factors such as taste preference for unhealthy foods and perceived lack of time to eat healthfully were longitudinally associated with higher fast-food intake among females. This consistency of findings across the life span lends itself to the development of population-based interventions that can use similar strategies to affect both adults' and adolescents' fast-food habits.

Strengths of the current study include its longitudinal design and use of a racially, ethnically and socioeconomically diverse population. The large sample size of Project EAT allowed for the examination of genderspecific relationships between socio-environmental, behavioural and personal factors and fast-food intake. A limitation of the study was its dependence on a single measure of fast-food intake. While this measure has been used in several other studies ${ }^{(14,21,25)}$, the item inquired only about the participant's fast-food intake in the past week, assuming that this reflects usual intake. Additionally, new types of fast-food restaurants are rapidly becoming available, expanding the concept of what is considered 'fast food' beyond hamburgers and fried chicken and into such realms as ethnic fast foods ${ }^{(30)}$. This diversity adds to the complexity of accurately assessing fast-food intake. Future research is needed to gain a deeper understanding of which fast-food restaurants adolescents frequent and what food choices are made. This is especially important in light of the healthier options being offered by some fast-food chains ${ }^{(31)}$ and the growing encouragement for fast-food restaurants to better inform their patrons of healthier meal options ${ }^{(32)}$.

\section{Conclusions}

Fast-food intake has been shown to be associated with weight gain and poor dietary choices among children, adolescents and adults ${ }^{(1,11,13-16)}$. Efforts to help adolescents reduce their fast-food intake may result in the achievement or maintenance of a healthier weight, along with better dietary intake, during a critical age where individuals increasingly need to make independent food decisions and prepare themselves for the transition into young adulthood. The results of the current, 5-year longitudinal study provide insight into strategies that may be successful to help high-school-aged adolescents decrease their fast-food intake. Our findings suggest the importance of addressing socio-environmental factors such as acculturation and home food availability. Additionally, gender-specific intervention strategies such as working with boys' sports teams, family members and peer groups, and for girls, emphasizing the importance of healthy weight-maintenance strategies and the addition of flavourful and healthy food options, may help to reduce fast-food intake.

\section{Acknowledgements}

We would like to thank Mr Peter Hannan for his statistical assistance with this paper. The study was supported by Grant R40 MC 00319 (D.N.-S., Principal Investigator) from the Maternal and Child Health Bureau (Title V, Social Security Act), Health Resources and Services Administration, US Department of Health and Human Services. K.W.B. is supported by the Adolescent Health Protection Program (School of Nursing, University of Minnesota) grant number T01-DP000112 (Principal Investigator: Bearinger) from the Centers for Disease Control and Prevention (CDC). The contents of this paper are solely the responsibility of the authors and do not necessarily represent the official views of the CDC. The authors declare that they have no competing interests. K.W.B., N.I.L., M.C.N., M.S. and D.N.-S. contributed to the study design; K.W.B. conducted the statistical analysis and wrote the manuscript; and all authors edited the manuscript and read and approved the final manuscript. D.N.-S. is the Principal Investigator of Project EAT-II.

\section{References}

1. Bowman SA, Gortmaker SL, Ebbeling CB, Pereira MA \& Ludwig DS (2004) Effects of fast-food consumption on energy intake and diet quality among children in a national household survey. Pediatrics 113, 112-118.

2. Guthrie JF, Lin BH \& Frazao E (2002) Role of food prepared away from home in the American diet, 1977-78 versus 1994-96: changes and consequences. J Nutr Educ Behav 34, 140-150.

3. Austin SB, Melly SJ, Sanchez BN, Patel A, Buka S \& Gortmaker SL (2005) Clustering of fast-food restaurants around schools: a novel application of spatial statistics to the study of food environments. Am J Public Health 95 , $1575-1581$.

4. Zenk SN \& Powell LM (2008) US secondary schools and food outlets. Health Place 14, 336-346.

5. Nestle M (2002) Food Politics: How the Food Industry Influences Nutrition and Health. Berkeley, CA: University of California Press.

6. Neumark-Sztainer D, French SA, Hannan PJ, Story M \& Fulkerson JA (2005) School lunch and snacking patterns among high school students: associations with school food environment and policies. Int J Behav Nutr Phys Act 2, 14.

7. Outley CW \& Taddese A (2006) A content analysis of health and physical activity messages marketed to African American children during after-school television programming. Arch Pediatr Adolesc Med 160, 432-435.

8. Powell LM, Szczypka G \& Chaloupka FJ (2007) Adolescent exposure to food advertising on television. Am J Prev Med 33, S251-S256.

9. Subar AF, Krebs-Smith SM, Cook A \& Kahle LL (1998) Dietary sources of nutrients among US children, 1989-1991. Pediatrics 102, 913-923.

10. Young LR \& Nestle M (2002) The contribution of expanding portion sizes to the US obesity epidemic. Am J Public Health 92, 246-249. 
11. Jeffery RW, Baxter J, McGuire M \& Linde J (2006) Are fast food restaurants an environmental risk factor for obesity? Int J Behav Nutr Phys Acti 3, 2.

12. Pereira MA, Kartashov AI, Ebbeling CB et al. (2005) Fastfood habits, weight gain, and insulin resistance (the CARDIA study): 15-year prospective analysis. Lancet $\mathbf{3 6 5}$, 36-42.

13. Taveras EM, Berkey CS, Rifas-Shiman SL et al. (2005) Association of consumption of fried food away from home with body mass index and diet quality in older children and adolescents. Pediatrics 116, e518-e524.

14. Schmidt M, Affenito SG, Striegel-Moore R et al. (2005) Fastfood intake and diet quality in black and white girls: the National Heart, Lung, and Blood Institute Growth and Health Study. Arch Pediatr Adolesc Med 159, 626-631.

15. Paeratakul S, Ferdinand DP, Champagne CM, Ryan DH \& Bray GA (2003) Fast-food consumption among US adults and children: dietary and nutrient intake profile. J Am Diet Assoc 103, 1332-1338.

16. Wiecha JL, Finkelstein D, Troped PJ, Fragala M \& Peterson KE (2006) School vending machine use and fast-food restaurant use are associated with sugar-sweetened beverage intake in youth. J Am Diet Assoc 106, 1624-1630.

17. French SA, Story M, Neumark-Sztainer D, Fulkerson JA \& Hannan P (2001) Fast food restaurant use among adolescents: associations with nutrient intake, food choices and behavioral and psychosocial variables. Int $J$ Obes Relat Metab Disord 25, 1823-1833.

18. Unger JB, Reynolds K, Shakib S, Spruijt-Metz D, Sun P \& Johnson CA (2004) Acculturation, physical activity, and fast-food consumption among Asian-American and Hispanic adolescents. J Community Health 29, 467-481.

19. Utter J, Scragg R \& Schaaf D (2006) Associations between television viewing and consumption of commonly advertised foods among New Zealand children and young adolescents. Public Health Nutr 9, 606-612.

20. Gordon-Larsen P, Harris KM, Ward DS \& Popkin BM; National Longitudinal Study of Adolescent Health (2003) Acculturation and overweight-related behaviors among Hispanic immigrants to the US: the National Longitudinal Study of Adolescent Health. Soc Sci Med 57, 2023-2034.

21. French SA, Harnack L \& Jeffery RW (2000) Fast food restaurant use among women in the Pound of Prevention study: dietary, behavioral and demographic correlates. Int J Obes Relat Metab Disord 24, 1353-1359.
22. Satia JA, Galanko JA \& Siega-Riz AM (2004) Eating at fastfood restaurants is associated with dietary intake, demographic, psychosocial and behavioural factors among African Americans in North Carolina. Public Health Nutr 7, 1089-1096.

23. Baranowski T, Perry C \& Parcel G (2002) How individuals, environments, and health behavior interact: social cognitive theory. In Health Behavior and Health Education: Theory, Research and Practice, 3rd ed., pp. 165-184 [K Glanz, B Rimer and F Lewis, editors]. San Francisco, CA: Jossey-Bass.

24. Neumark-Sztainer D, Story M, Perry C \& Casey MA (1999) Factors influencing food choices of adolescents: findings from focus-group discussions with adolescents. J Am Diet Assoc 99, 929-937.

25. Niemeier HM, Raynor HA, Lloyd-Richardson EE, Rogers ML \& Wing RR (2006) Fast food consumption and breakfast skipping: predictors of weight gain from adolescence to adulthood in a nationally representative sample. $J$ Adolesc Health 39, 842-849.

26. Larson NI, Neumark-Sztainer D, Story MT, Wall MM, Harnack L \& Eisenberg ME (2008) Fast food intake: longitudinal trends during the transition to young adulthood and correlates of intake. J Adolesc Health $\mathbf{4 3}$, 79-86.

27. Neumark-Sztainer D, Story M, Hannan PJ \& Croll J (2002) Overweight status and eating patterns among adolescents: where do youths stand in comparison with the Healthy People 2010 objectives? Am J Public Health 92, 844-851.

28. Little R (1986) Survey nonresponse adjustments for estimates of means. Int Stat Rev 54, 137-139.

29. Neuhouser ML, Thompson B, Coronado GD \& Solomon CC (2004) Higher fat intake and lower fruit and vegetables intakes are associated with greater acculturation among Mexicans living in Washington state. J Am Diet Assoc 104, $51-57$.

30. Sloan EA (2001) Top 10 trends to watch and work on: 3rd biannual report. Food Technol 55, 38.

31. Glanz K, Resnicow K, Seymour J et al. (2007) How major restaurant chains plan their menus: the role of profit, demand, and health. Am J Prev Med 32, 383-388.

32. Wootan MG, Osborn M \& Malloy CJ (2006) Availability of point-of-purchase nutrition information at a fast-food restaurant. Prev Med 43, 458-459. 